\title{
A new marine varanoid from the Cenomanian of the Middle East
}

\section{A. Haber ${ }^{\star}$ \& M.J. Polcyn}

Department of Geological Sciences, Southern Methodist University, Dallas, Texas 75275, USA.

* Corresponding author. Email: annat@uchicago.edu

Manuscript received: November 2004; accepted: February 2005

\begin{abstract}
We describe a new marine varanoid, Judeasaurus tchernovi gen. et sp. nov., on the basis of a partial skull recovered from the Middle Cenomanian of the Judean Hills. The new taxon possesses a unique suite of characters exhibited in terrestrial varanoid lizards on the one hand and derived mosasauroids on the other. The characters that relate it to terrestrial varanoid lizards include broad premaxilla, anteriorly depressed maxillae underlying the nasal capsule, extensive postorbitofrontal-parietal contact and vertically oriented parietal rami. Derived mosasauroid characters include a question-mark shaped quadrate, fused frontals, intricate fronto-parietal suture and moderately retracted nares. The shape of the supratemporal and its syndesmotic articulation with the parietal distinguishes the new taxon from any other known specimen. The dentition exhibits elongate and narrow cylindrical roots lacking resorption pits, a condition reminiscent of Coniasaurus, but crowns are small, slightly recurved and conical. Taken together, the new taxon possesses a suite of characters suggesting dolichosaurid affinities.
\end{abstract}

Keywords: Varanoidea, Dolichosauridae, mosasaurs, Coniasaurus, Cretaceous, Middle East

\section{Introduction}

In the present paper we name and describe a new marine varanoid from near Jerusalem. Although incomplete, the specimen includes important features of the skull roof, the temporal arch and the quadrate, and a combination of characters that relate it to both terrestrial (e.g., Varanus spp. and Estesia mongoliensis) and marine (e.g., mosasauroids and dolichosaurs) varanoid lizards.

Fossils found in the eastern Mediterranean document the diversity of marine varanoids (sensu McDowell \& Bogert, 1954; Platynota sensu Rieppel, 1980) from the Cenomanian of northeastern Gondwana (Russell, 1967; deBraga \& Carroll, 1993; Carroll, 1997, Dal Sasso \& Pinna, 1997; Caldwell \& Cooper, 1999; Dal Sasso \& Renesto, 1999; Polcyn et al., 1999, 2003; Caldwell, 2000; Lee \& Scanlon, 2002; Rieppel et al., 2003), including basal mosasauroids and the closely related dolichosaurs, providing an opportunity to study the transition of tetrapods from terrestrial to marine environments. Such studies require well-established phylogenies; however, relationships amongst dolichosaurids and basal mosasauroids remain largely unresolved. Further, of the nine characters previously diagnosing Mosasauroidea (sensu G.L. Bell, 1997), three have now been documented within Dolichosauridae (Dal Sasso \& Pinna, 1997; Caldwell \& Cooper, 1999; Caldwell, 2000; Pierce \& Caldwell, 2004), including extreme reduction in posteromedial process of the coronoid, circular configuration of quadrate and a derived intramandibular joint. The six remaining characters can be divided into three complexes: 1 - three characterising the lower jaw and dentition; 2 - one characterising the frontal invasion by the external nares; and 3 - two characterising tail modifications for a sculling organ. All of these are arguably subject to homoplasy resulting from secondary marine adaptations, albeit the dental characters less so. The paucity of characters unambiguously diagnosing Mosasauroidea and the apparent mosaic of derived and plesiomorphic characters 
present in basal members of secondarily derived marine varanoids underscores the importance of documentation of new forms that may aid the discovery of useful characters contributing to more robust phylogenetic analyses. Although such a phylogenetic analysis is beyond the scope of the present study, we aim to provide a detailed description of the prepared portions of the specimen and discuss its possible relationships with other marine varanoids. The importance of this specimen is in its contribution of character information that was previously not available from the fossil record and in documenting a unique suite of characters in a midCenomanian marine varanoid.

\section{Abbreviations}

BMNH - The Natural History Museum (The British Museum), London; FMNH - Field Museum of Natural History, Chicago; HUJI - Hebrew University of Jerusalem, Israel; MSNM - Museo Civico di Storia Naturale di Milano, Milano, Italy; YPM - Yale Peabody Museum.

\section{Geological context}

The specimen was collected by an enthusiast and donated to the palaeontological collections of the Hebrew University of Jerusalem (Israel). Collection data do not specify the exact locality and formation to which it belongs, but it is known to come from one of the Cenomanian-Turonian fish localities of the Judean Hills surrounding Jerusalem. Both biostratigraphic and lithological analyses were conducted in an attempt to further constrain the age of the specimen.

Our lithological analyses indicate that the sedimentary matrix consists mostly of pinkish-grey limestone, with 95\% $\mathrm{CaCO}_{3}$. Clay and dolomite are rare, as suggested by the small amount of $\mathrm{Al}(0.88 \%)$, Si $(1.11 \%)$ and $\mathrm{Mg}(0.60 \%)$. The mineral composition suggests that the depositional environment was shallow, low-energy, marine water with little or no terrigenous input. Conspicuous, red, iron-rich bands and lack of bioturbation also confirm a low-energy deposition. Microfossils could not be extracted by acid digestion, oxidisation and sieving due to diagenetic calcification and amalgamation, but they were visible in thin section. Thin sections of the matrix revealed a high density of planktonic ooze, including the planktonic foraminifer Hedbergella. The high occurrence of planktonic foraminifera suggests a connection to open marine environment. Yet, the lack of foraminifera such as Rotalipora rules out the option that the locality was within an open marine setting and supports the interpretation of a local basin on a continental shelf. Hedbergella spp. in the Judean Hills are most commonly found in mid-Cenomanian to lower Turonian sections (Hamaoui \& Raab, 1965; Arkin \& Hamaoui, 1967; Buchbinder et al., 2000), that is, in the range of 95-93 Ma (Gradstein et al., 1995; Buchbinder et al., 2000).
The lithological and biostratigraphical results point to either the Laminated Limestone ('Dir Yasin') Member of the Kefar Sha'ul Formation or the lower member of the Bina Formation ('Mizzi Ahmar'), as the most probable source formations for the specimen (A. Almogi-Labin, B. Buchbinder, Y. Arkin, Z. Lewy and Y. Chalifa, pers. comm.). Both belong to the Judea Group.

The Kefar Sha'ul Formation is characterised by low-energy basinal facies (Raab, 1958; Hamaoui \& Raab, 1965; Raab \& Chalifa 1987; Taitel-Goldman et al., 1995; Lewy, 1996; Buchbinder et al., 2000) and consists of two members: a lower Limestone Member which is more massive, argillaceous and yellowish, and an upper pinkish-grey Laminated Limestone Member (Arkin et al., 1965; Lewy, 1996). The upper member marks the transition between the mid- and upper Cenomanian, concurrent with the first appearance of the ammonite species Neolobites vibrayeanus in the area as well as globally (Lewy, 1996). Both members of the Kefar Sha'ul Formation are rich in ammonites, and the upper member is also rich in fish fossils. The fish fossils from the upper Laminated Limestone Member of Kefar Sha'ul Formation are embedded in a matrix very similar to that of the specimen described herein. It consists of yellowish-grey to pinkish-grey, thin-bedded, platy, finegrained limestone (Raab, 1958; Raab \& Chalifa, 1987; pers. obs.), and the iron-rich red bands conform to the shapes of the fossils (Raab, 1958; pers. obs.). The Kefar Sha'ul Formation is exposed as several patches at the eastern flanks of the Judean Hills anticline (Arkin \& Hamaoui, 1967; Arkin, 1976). The upper member is more confined geographically than the lower member. The fish-bearing strata have been found mainly in the western outskirts of Jerusalem, and in one restricted occurrence near Ramallah (Raab \& Chalifa, 1987).

The Bina Formation is also characterised by shallow and warm marine environment (Hamaoui \& Raab, 1965). The lower member (the 'Mizzi Ahmar' lithofacies) consists of finely crystalline, reddish-pinkish limestone or dolostone beds alternating with marl (Arkin et al., 1965; Arkin \& Hamaoui, 1967; Buchbinder et al., 2000). Its lower part is within the $N$. vibrayeanus Zone, correlated with the drowning event of the upper Cenomanian that is prominent in all parts of Israel (Lewy, 1989; Buchbinder et al. 2000). The 'Mizzi Ahmar' lithofacies, however, represent a condensed section and were deposited on a residual high at the time of the drowning event (Buchbinder et al., 2000). Hedbergella is very common in these facies (Hamaoui \& Raab, 1965; Buchbinder et al., 2000) and some fishes were found as well ( $Z$. Lewy, pers. comm.). It is exposed around Jerusalem, wedging northeast towards the Sumerian Hills (Arkin \& Hamaoui, 1967; Arkin, 1976).

\section{Systematic palaeontology}

Order Squamata

Superfamily Varanoidea 


\section{Judeasaurus gen. nov.}

Etymology - After the Judean Hills where the holotype was presumably found.

Type and only known species - Judeasaurus tchernovi sp. nov.

Diagnosis - As for species.

Etymology - In honour of the late Professor Eitan Tchernov, for his contribution to the study of palaeontology in Israel.

Holotype - HUJI P4000, incomplete skull, including right maxilla with five anterior teeth, a right jugal, fused frontals and parietals, both postorbitofrontals, supratemporals, squamosals, quadrates and partial mandibles, fragments of cervical vertebrae.

Type locality and horizon - Unknown locality in the Judean Hills of either Israel or the West Bank; most likely from either the upper Laminated Limestone Member of Kefar Sha'ul Formation, upper Cenomanian, or the lower member of Bina Formation, lower Turonian.
Diagnosis - Distinguished from other varanoids by the conical shape of the parietal process of the supratemporal and the way it is nested syndesmotically within the lateral wall of the parietal suspensorial ramus, and by the following unique combination of characters: broad premaxilla, nasal capsule floored by the anterior part of the maxilla, postorbitofrontalparietal contact at least as extensive as postorbitofrontalfrontal contact, suspensorial arcade is almost vertical, concave 'question-mark'-shaped quadrate with well-developed suprastapedial process and tympanic ala, fused frontals, Mshaped fronto-parietal suture, weakly developed descending processes of the frontal, moderately retracted nares, closely spaced teeth with narrow bases, 14 - 16 mandibular teeth, no plicidentine.

Description - The specimen is a skull exposed in ventral view on a small flag of limestone, and includes a fragmentary right maxilla with five anterior teeth, a right jugal, fused frontals and parietals, both postorbitofrontals, supratemporals, squamosals and quadrates (Fig. 1). A calcareous mass obscures the occipital region. Fragments of postdentary bones are preserved from both sides, and the right dentary is exposed on its lateral side,

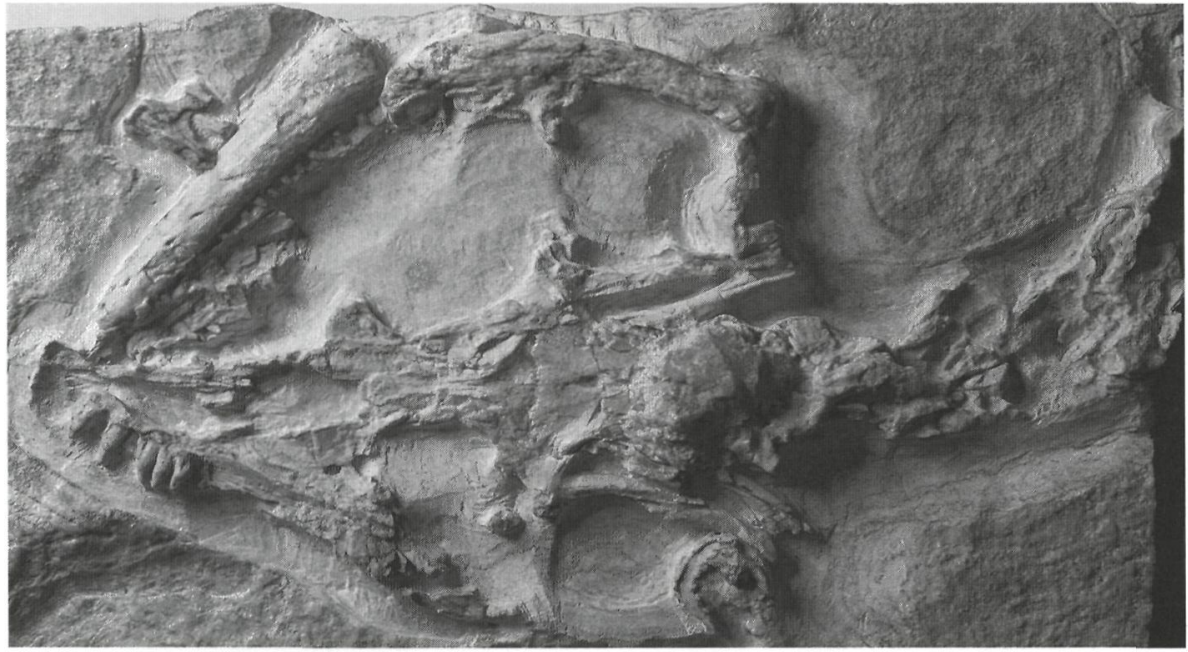

a.

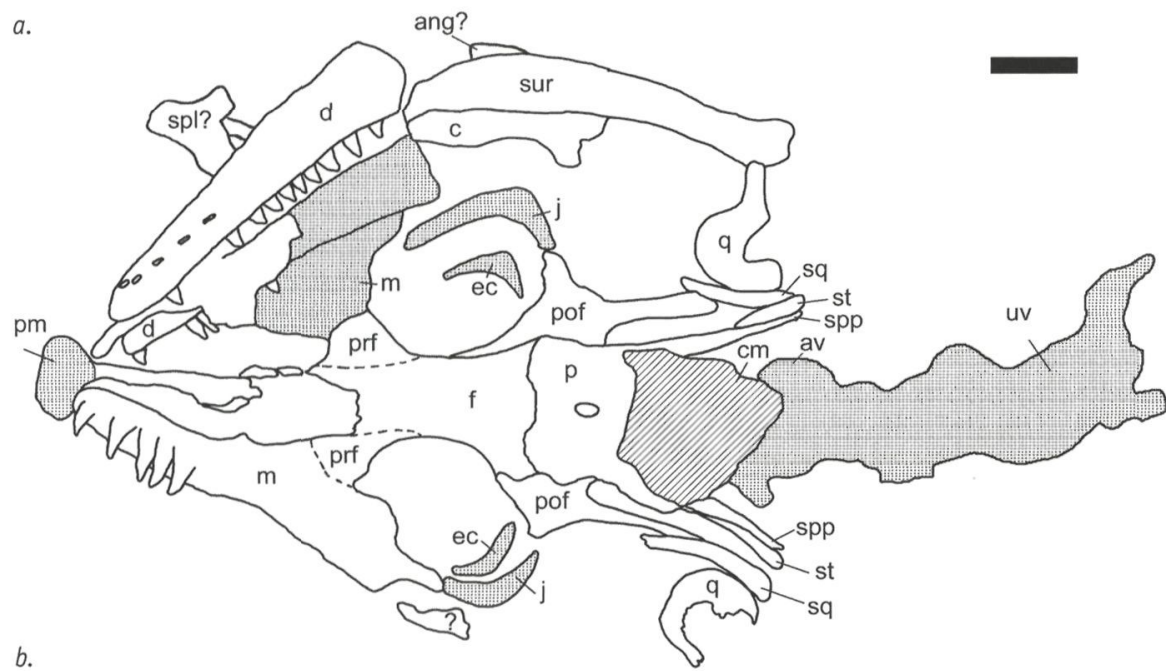

Fig. 1. Judeasaurus tchernovi (HUJI P4000, holotype) in ventral view: a. photograph; and $b$. interpretive drawing. Stippled areas represent elements that were preserved as impressions. Abbreviations: ang: angular; av: atlas vertebrae; $c$ : coronoid; $\mathrm{cm}$ : calcarious mass; $d$ : dentary; ec: ectopterygoid; j: jugal; $f$ : frontal; $m$ : maxilla; $p$ : parietal; pm: premaxilla; pof: postorbitofrontal; pr: prefrontal; q: quadrate; spl: splenial; spp: suspensorial process of parietal; sq: squamosal; st: supratemporal; sur: surangular; uv: undifferentiated vertebrae. Scale bar equals $10 \mathrm{~mm}$. 
overlying the left dentary. Remnants of the left maxilla are visible between the two dentaries. The anterior cervical vertebrae are represented by impressions in the matrix and a few uninformative fragments. The orbital and preorbital portions together are almost twice as long as the postorbital region.

The premaxilla is preserved as an impression of the dorsal surface, which shows a single element, relatively wide and slightly convex, low in lateral profile and was apparently tightly attached to the anteriorly depressed maxillae. Narrow fragments of bone extend from the premaxilla impression towards the frontal, but it is difficult to decipher whether these are remnants of the nasals or the premaxilla internarial bar. Impressions of the external nares are visible in pictures that were taken before the first attempt to prepare the specimen, and together with the preserved narial emargination of the maxilla suggest that the external nares were moderately retracted.

The right maxilla is exposed medially. The slightly concave, horizontal surface of its anterior portion of the maxilla forms the ventral border of the nasal capsule (Fig. 2). The latter covers almost half of the maxilla, and ends approximately above the sixth tooth, where the maxillary ascending process and narial emargination begin. The ascending process extends dorsally to at least twice the height of the anterior process of the maxilla. The exact suture with the prefrontal is difficult to decipher in internal view because the prefrontal overlaps the maxilla medially to it. An oval foramen $2 \mathrm{~mm}$ in diameter, located just ventral and posterior to the presumed suture, is possibly the lacrimal foramen. Unidentifiable fragments obscure the posterior portion of the maxilla, but the shape of the preserved portion suggests that it extended to occupy 30 - $50 \%$ of the suborbital margin.

The jugals were preserved as impressions. They were robust and L-shaped, with no posteroventral process. The shape of the jugals, along with the long and robust jugal processes of the postorbitofrontals, suggests they were in contact.

The ectopterygoids were also visible in pictures as impressions with some remnants of bone. They are found medial to the jugals and are smaller and more angular.

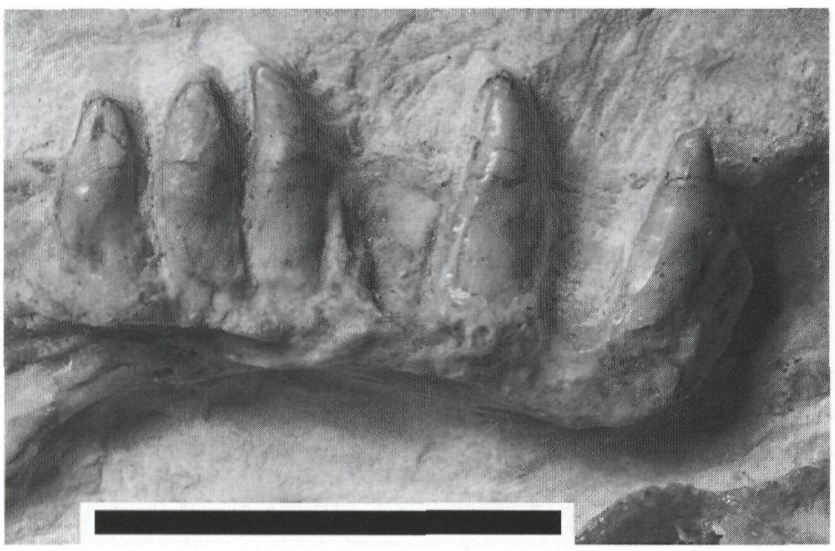

Fig. 2. Judeasaurus tchernovi, anterior part of right maxilla in medial view. Scale bar equals $5 \mathrm{~mm}$.
The ventral surfaces of both prefrontals are visible posterior to the maxilla. They are triangular, widest at their contact with the maxilla and taper posteriorly. It is not possible to decipher the contact between the prefrontals and the frontal.

The frontal is a single fused element, seen in internal view. The lateral edges of the frontal are deflected smoothly inwards towards the midline, where a longitudinal recess is found for the olfactory canal. Although broken, the inward deflection of the lateral edges suggests that the descending processes of the frontal were developed to some degree. The lateral edges are concave above the orbit, rendering the posterior corners of the frontal ala acuminate and laterally oriented. The anterior margin of the frontal is broken, therefore its relationships to the nasals and the nares are obliterated. The maximum length to maximum width ratio is at least 1.6. The ventral aspect of the frontoparietal suture is wide and transverse, wider than both the anterior margin of the frontal and the posterior margin of the parietal, and is an intricate M-shape rather than straight, with lateral wings of the frontal overlapped by the parietal. Given the oblique nature and complex interdigitation seen in other mosasauroids this may not be representative of the sutural pattern in dorsal view.

The parietal is also a single fused element, with a total length of about $15 \mathrm{~mm}$. A large elliptic pineal foramen (2 mm long and $1 \mathrm{~mm}$ wide) lies $5 \mathrm{~mm}$ posterior to the frontoparietal suture, leveled with the parietal table. The posterior end of the parietal and the occipital unit are obscured by a calcareous mass. Fragments of what are most likely the (well-developed) parietal descending processes, or possibly the antero-superior processes of the prootics, are found posterior to the foramen magnum, and apparently have collapsed medially during postdepositional deformation. Long suspensorial rami extend posterolaterally (Fig. 3). Each ramus is slightly mediolaterally compressed with a vertical orientation. A groove in the lateral wall receives the parietal process of the supratemporal, and extends anteriorly about half the length of the suspensorial rami.

The postorbitofrontals are preserved on both sides, with no clear suture separating the postfrontal from the postorbital. The main body of this element, from the base of the jugal process to its contact with the frontoparietal suture, is bulky and stout and is expanded laterally to almost half the length of the frontoparietal suture. The squamosal and the prefrontal processes of the postorbitofrontal meet each other at about $120^{\circ}$. The parietal process is well developed, excluding the parietal from the anterior half of the medial margin of the supratemporal fenestra. The postorbitofrontal-parietal contact is at least as expanded as the postorbitofrontal-frontal contact. The jugal process is better preserved on the left side. It is thick and conical, and extends to about the same length as the main body of the postorbitofrontal. The prefrontal process ends anteriorly in an amalgam of fragmented bones, thus it is impossible to determine the extent to which it participated in the dorsal margin of the orbit. The prefrontal and parietal 


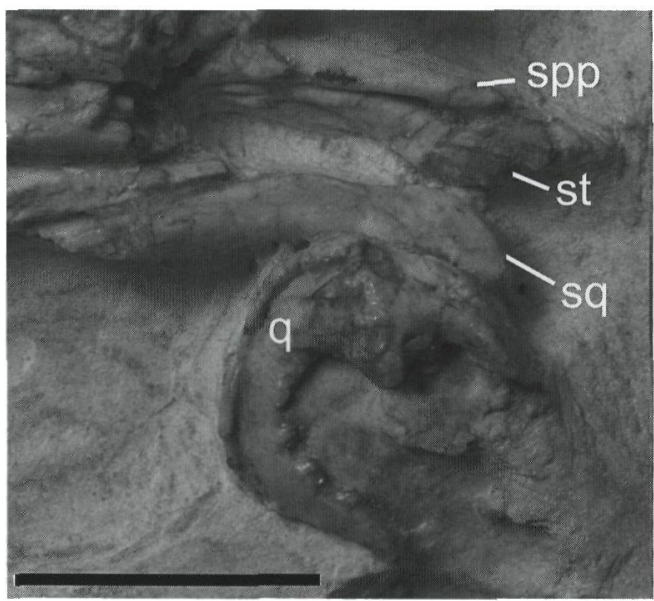

a.

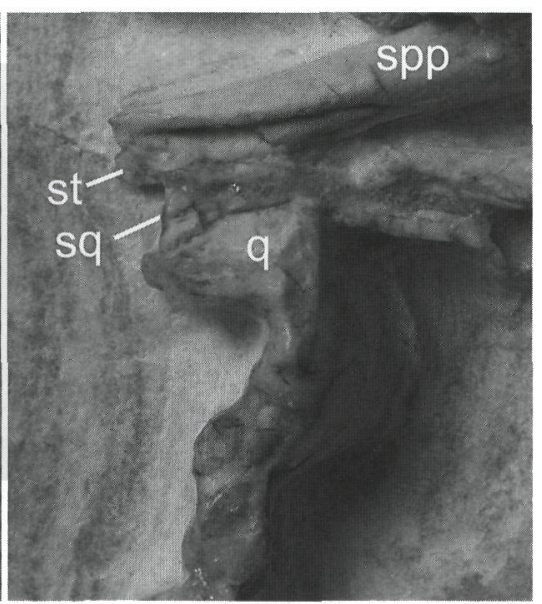

b.

Fig. 3. Judeasaurus tchernovi, a. right; and b. left quadrates and suspensorial arcades in medial view. Scale bar equals $10 \mathrm{~mm}$.

processes are smoothly continuous with the squamosal and jugal processes.

Both the squamosals are broken in the middle but otherwise well preserved. The similarity in the breakage suggests that the squamosal's posterior halves on both sides were twisted as they were forced to splay laterally along with the quadrates. The anterior ends meet the postorbitofrontals to form complete temporal arches and rather narrow and elongated supratemporal fenestrae. The squamosal shafts are narrow and elongate with no ventral process. There is a curved depression on the medial aspect of the right squamosal, where the postorbitofrontal probably articulated. The posterior parts are comma-shaped, capping the quadrate cephalic condyle.

The parietal process of the supratemporal is conical in shape, tapering anteriorly (Fig. 3), and nested within the suspensorial ramus of the parietal. The articulation surface is rounded and smooth, suggesting a syndesmotical joint between the supratemporal bone and the ramus. Both the supratemporals appear to be broken, with their posterior ends missing, indicating that they may have extended beyond the end of the suspensorial rami of the parietal, which terminate with a round and finished bone. The exoccipital contact is obscured.

The quadrates are exposed in medial view. The left quadrate lies on a lower plane than the right and therefore is less eroded, but the suprastapedial process is better preserved on the right quadrate. The left quadrate has the distinct shape of a question-mark in medial view (Fig. 3), with the dorsal twothirds of the bone uniformly concave posteriorly, and the ventral part descending vertically down to meet the articular facet of the mandible. Because the quadrate is tightly articulated with the mandible, it is not possible to determine the shape of the articular surface. The lateral aspect is not exposed but a serrated ridge is visible running vertically along the tympanic ala which appears to be unique to this taxon. The infrastapedial process is apparently not strongly developed. The medial surface is too eroded to clearly preserve the stapedial pit; however, an elongate depression can be seen just anterior to the suprastapedial notch and may represent the stapedial pit.
The right dentary is exposed on its lateral side. Its position on top of the left dentary suggests they were possibly bound to each other to some degree in the live animal. Six mental foramina can be clearly identified, and two more may be obliterated by cracks posteriorly. The posterior end is broken and the intramandibular joint cannot be traced. The lateral aspect of the post-dentary bones is eroded and the posterior margin of the retroarticular process is broken. The coronoid, however, is obviously prominent.

Twelve teeth are preserved on the dentary. Room for two more is present at the anterior portion, covered by fragments of the left maxilla. The dentary rises dorsally posterior to the last tooth preserved, indicating that there are probably no more than two teeth missing from the posterior end. Thus, the total reconstructed number is no more than 16. The conical, slightly recurved teeth are uniform in size and shape. Tooth implantation cannot be determined until the lingual side of the dentary is exposed.

Five teeth are preserved on the anterior third of the maxilla with room for seven total, showing a pleurodont mode of attachment with no apparent resorption pits (Fig. 2). The tooth bases are tall and narrow and in contact with one another. The crown comprises approximately one third of the total tooth height with no constriction at the junction of the crown and root. The teeth are uniform in size and shape, which is conical and only slightly recurved. No wear facets and no carinae are visible on the teeth, and the enamel is smooth. A small apical foramen is visible at the base of the third tooth.

\section{Comparisons}

Judeasaurus exhibits several squamate synapomorphies (compare Gauthier et al., 1988): the premaxillae are fused; the coronoid process is prominent; the frontoparietal suture is transverse and wide; the parietals are fused; the supratemporal sits in a deep ventral position, anterior to the parietal ramus, as opposed to a superficial position posterior to it; the ventral ramus of the squamosal and the posterior process of the jugal 
are absent (lower temporal arch is lost); the quadrate process of the squamosal is reduced, with the squamosal abutting the quadrate rather than capping it; and the attachment of the pterygoid to the quadrate is loose. It is autarchoglossan based on the loss of jugal-squamosal contact on the temporal arch (Estes et al., 1988). The specimen is a varanoid based on the fused postorbitofrontal, long supratemporal that reaches the parietal notch, retracted nares associated with a posterior position of the ascending processes of the maxilla, posterior end of maxilla anterior to middle of orbit, reduction of subdental shelf and lack of resorption pits (Bahl, 1937; Edmund, 1969; Rieppel, 1980; Pregill et al., 1986; Estes et al., 1988; Norell et al., 1992; Lee, 1997; Zaher \& Rieppel, 1999). The presence of pineal foramen, postorbital and temporal arch in Judeasaurus probably excludes Lanthanotus and Heloderma as its closest relatives.

The specimen can be distinguished from terrestrial varanoid lizards, both Recent (sensu Estes et al., 1988) and fossil (e.g., Estesia mongoliensis Norell et al., 1992; Megalania prisca Hecht, 1975) by the conical shape of the parietal process of the supratemporal, the closely spaced teeth with no plicidentine, the concave 'question-mark' shaped quadrate, the intricate $\mathrm{M}$-shaped frontoparietal suture, and the fused frontals. These characters, with the exception of the first, relate the specimen to mosasauroids (sensu G.L. Bell, 1997). However, several features that distinguish derived mosasaurs from other varanoids are not present in Judeasaurus, thus inviting comparison with specimens of more basal mosasauroids and dolichosaurs. These features include the lack of the descending processes of the frontal, the maxillary association with the nasal capsule and with the narial emargination, the extent of the postorbitofrontal-parietal contact, the orientation of the quadrate suspensorium complex and tooth implantation.

Varanoids are characterised by well-developed descending processes in the ventral surface of the frontal, which embrace the olfactory canal (Bahl, 1937; McDowell \& Bogert, 1954; Rieppel, 1980; Estes et al., 1988; Norell et al., 1992). These processes have been reduced and lost in basal mosasauroids such as Tethysaurus (Bardet et al., 2003), Halisaurus (G.L. Bell, 1997) and Clidastes (Russell, 1967; G.L. Bell, 1997). The descending processes of Judeasaurus are probably weakly developed, but the inward deflection of the lateral edges (Fig. 1a) resembles the typical varanoid condition more than the mosasauroid condition, where there is no deflection at all (e.g.. Halisaurus sternbergii, FMNH PR186, pers. obs.; Clidastes propython, YPM 1368; Russell, 1967). Coniasaurus gracilodens shows an inward deflection of the frontal lateral edges with weakly developed descending processes (Caldwell, 1999) similar to Judeasaurus, and the frontal dimensions are also similar. They differ, however, in their tooth shape and count, as discussed below.

The anterior part of the maxilla of terrestrial varanoid lizards forms a medially-projected shelf that underlies the nasal capsule (Bahl, 1937; McDowell \& Bogert, 1954; Norell et al., 1992; DeBraga \& Carroll, 1993), whereas in mosasauroids it is vertical throughout, bordering the external nares laterally, as reported for Opetiosaurus buccichi (Carroll \& deBraga, 1992), for Tethysaurus nopcsai (Bardet et al., 2003) and for all other mosasauroids (Russell, 1967). The maxilla of Judeasaurus is clearly of plesiomorphic varanoid morphology (Fig. 2).

In terrestrial varanoid lizards, the postorbitofrontal-parietal contact is at least as extensive as the postorbitofrontal-frontal contact (Bahl, 1937; McDowell \& Bogert, 1954). In all Varanus species (Bahl, 1937; Frazzetta, 1962) and in Estesia mongoliensis (Norell et al., 1992) the parietal process of the postorbitofrontal forms the anterior margin of the supratemporal fenestra. In Tethysaurus nopcsai (Bardet et al., 2003), Halisaurus platyspondylus (Holmes \& Sues, 2000) and most mosasaurids (Russell, 1967; deBraga \& Carroll, 1993) the prefrontal and the parietal processes of the postorbitofrontal do not enclose a lateral lobe from the parietal as much as they do in other varanoids, rendering a looser articulation between the postorbitofrontal and the parietal. Carroll \& DeBraga (1992) observed a broad postorbitofrontal-parietal suture for Aigialosaurus dalmaticus and Opetiosaurus buccichi, similar to what is seen in Judeasaurus (Fig. 1).

The orientation of the suspensorium arcade has been cited as a critical transformation in the evolution of mosasauroids (Russell, 1967; DeBraga \& Carroll, 1993; G.L. Bell, 1997; Holmes \& Sues, 2000). The parietal suspensorial rami of terrestrial varanoid lizards are mediolaterally compressed and vertical (Bahl, 1937) whereas in derived mosasauroids they assume a horizontal orientation (Russell, 1967), affecting their association with the supratemporal, squamosal and paroccipital process and their role in cranial kinesis. Holmes \& Sues (2000) described a unique combination of varanoid and mosasauroid features for Halisaurus platyspondylus, in which the parietal suspensorial ramus is vertical at the point of divergence from the parietal table, yet oblique in its posterior end, forming an angle of about 55 degrees with the horizontal. Similar to derived mosasauroids, the suspensorial ramus of the parietal is short and loosely articulated with the supratemporal, yet, unlike derived mosasauroids, the occipital unit of the braincase is firmly attached to the ventral surface of the parietal. However, Bardet et al. (2003) report that Tethysaurus nopcsai, which was reconstructed as a more basal mosasauroid than Halisaurus based on a suite of characters, had horizontal parietal suspensorial rami. According to Carroll \& deBraga (1992), Aigialosaurus dalmaticus and Opetiosaurus buccichi retained the varanoid vertical orientation. Judeasaurus resembles $A$. dalmaticus and 0 . buccichi in retaining the varanoid vertical orientation (Fig. 3 ), yet the conical shape of its supratemporal and the way it is nested within the parietal suspensorial ramus with a syndesmotic articulation are unique to this specimen and distinguish it from terrestrial varanoid lizards as well as from all known mosasauroids. 
Tooth implantation of squamates was reviewed by Zaher \& Rieppel (1999). Specifically, they redefined the three basic modes of tooth implantation (acrodonty, pleurodonty and thecodonty) and the three variations of pleurodonty (full pleurodonty, labial pleurodonty and subpleurodonty) based on tooth attachment and tooth replacement. Terrestrial varanoid lizards are characterised by full pleurodonty, where a basal plate is absent, interdental ridges are poorly developed and the teeth are in basal contact with each other. However, derived mosasauroids developed a specialised mode of full pleurodonty, with large and inflated bony bases of attachment, resorption pits and no plicidentine, whereas terrestrial varanoid lizards have teeth with fluted bases, plicidentine and no resorption pits (Zaher \& Rieppel, 1999). Basal mosasauroids show various combinations: Tethysaurus nopcsai has no resorption pits with 'minute ridges on the lower half of the crown' (Bardet et al., 2003); Haasiasaurus gittelmani, a primitive mosasauoid from the Middle East, has bony bases of attachment but no resorption pits (Polcyn et al., 1999, 2003); and there is no evidence so far for resorption pits in Aigialosaurus dalmaticus and Opetiosaurus buccichi, but there is some development of bone of attachment (Carroll \& deBraga, 1992). Judeasaurus has full pleurodonty tooth implantation with no plicidentine. However, no resorption pits can be observed either.

From what is known of Aigialosaurus dalmaticus and Opetiosaurus buccichi (Carroll \& deBraga, 1992), and from Haasiasaurus gittelmani (Polcyn et al., 1999, 2003), primitive mosasauroids resemble recent varanoid lizards, as does Judeasaurus, in the fusion of postorbital with postfrontal, the extensive postorbitofrontal-parietal contact, the retracted nares and the orientation of the suspensorium complex, and relate to derived mosasauroids by having fused frontals and question mark-shaped quadrates. However, unlike Judeasaurus, they acquired the mosasaur condition of vertical anterior maxilla, rather than the varanoid condition in which the anterior portion of the maxilla underlies the nasal capsule. Aigialosaurus dalmaticus, like Judeasaurus but unlike 0 . buccichi and other mosasauroids, has narrow tooth bases and narrow conical teeth (Carroll \& deBraga, 1992). However, the reconstructed tooth count for those genera is 22 to 28 for mandibular teeth, while Judeasaurus could hold no more than 16 teeth in its mandible. The teeth of Haasiasaurus gittelmani are weakly striated with well-developed carinae and the reconstructed tooth count is 24 for the mandible (Polcyn et al., 1999, 2003).

Other marine varanoids from the Upper Cretaceous comparable to Judeasaurus include Coniasaurus and several other specimens that were grouped together by Nopcsa (1903) as Dolichosauridae. These specimens, however, are fragmentary and poorly preserved, and the group was recently found paraphyletic by Pierce \& Caldwell (2004). Comparison with Dolichosaurus longicollis is not possible because cranial material of this genus is too fragmentary (Caldwell, 2000).
Cranial remains of Aphanizocnemus libanensis (Dal Sasso \& Pinna, 1997) are also badly preserved, but it seems to have fused frontals and a circular shaped quadrate. It is, however, about half the length and width of Judeasaurus. The single known tooth of Aphanizocnemus libanensis is conical with a pointed tip and probably full pleurodont implantation, similar to teeth of Judeasaurus. Other elements are insufficiently preserved to be compared. Specimen V3662, housed at the MSNM, an undetermined dolichosaur from Lebanon (Dal Sasso \& Renesto, 1999), has a circular quadrate and fused frontals, but it also has teeth with expanded bony bases and other characters that relate it to the more derived mosasauroids.

Adriosaurus was redescribed and reassessed by Lee \& Caldwell (2000) and Caldwell \& Lee (2004). Similar to Judeasaurus, the anterior part of the maxilla of Adriosaurus bends medially to form the ventral border of the external nares and the frontoparietal suture is M-shaped, but unlike Judeasaurus and probably all other dolichosaurs, the frontals are paired rather than fused. The teeth are too poorly preserved to be compared. Pontosaurus was also redescribed by Pierce \& Caldwell (2004), who indicated that the frontals were fused into one median element and the suspensorium orientation was vertical or oblique, but the frontoparietal suture straight and simple and the postorbital not fused to the postfrontal.

Both the British (Caldwell, 1999; Caldwell \& Cooper, 1999) and the North American (B.A. Bell et al., 1982) remains of Coniasaurus crassidens were diagnosed based on tooth shape and heterodonty. Caldwell (1999) assigned BMNH R44141 to Coniasaurus, as a new species $C$. gracilodens, mainly based on the increased robustness of posterior maxillary teeth. Coniasaurus remains from Texas were also diagnosed by the progressively increased thickness of the posterior marginal teeth, their laterally compressed shape and the longitudinal grooves on their posterior surface (B.A. Bell et al., 1982). Although both $C$. crassidens and Judeasaurus have closely spaced teeth with no plicidentine, they differ in their shape: the maxillary teeth of HUJI 4000 are conical rather than laterally compressed and have none of the crenulations, carinae or sulci reported for C. crassidens by Caldwell \& Cooper (1999). Neither does it have the resorption pits reported for $C$. gracilodens (Caldwell, 1999). The shape of the dentary is similar to that of Coniasaurus, with no curvature in lateral view, but the tooth shape and tooth count is different. Caldwell \& Cooper (1999) reconstructed 21-22 mandibular teeth. Judeasaurus shows no heterodonty and the mandibular teeth are conical and symmetrical rather than bipartite and bulbous. Similar to $C$. crassidens but unlike $C$. gracilodens, the ascending process of the maxilla of Judeasaurus begins above the 6th maxillary tooth rather than the second.

Judeasaurus can be distinguished from all known mosasauroids (sensu G.L. Bell, 1997) by the shape of the supratemporal and its articulation with the parietal suspensorial ramus, and by its unique combination of characters as listed 
in the diagnosis. It is most likely affiliated with the group of specimens known as dolichosaurs, but it cannot be assigned to any known taxon within that group.

\section{Summary}

The specimen described here comes from the Cenomanian deposits of the Judea Group of the Middle East, probably from the western side of Jerusalem, Israel. Geographically the Judea Group was deposited on the northwestern shelf of the Arabo-Nubian plate. Biostratigraphic and lithostratigraphic analyses point to the upper Laminated Limestone Member of Kefar Sha'ul Formation as the most probable source formation for the specimen, correlated with the middle to upper Cenomanian boundary and concurrent with the first appearance of the ammonite species Neolobites vibrayeanus and is dated at approximately $94 \mathrm{Ma}$. The depositional environment is reconstructed as a restricted basin, with some connection to open ocean pelagic environments.

Judeasaurus tchernovi represents a new taxon within Varanoidea, related to mosasauroids based on its fused frontals and circular quadrate. It possesses a unique combination of characters of both marine and terrestrial varanoid lizards and is unique among varanoids in the shape of its supratemporal and in the way the supratemporal is syndesmotically nested within the suspensorial ramus of the parietal. It is affiliated with previously described varanoids found in marine rocks of the Upper Cretaceous such as Aphanizocnemus and Dolichosaurus, although the information currently available for these taxa is insufficient to determine their exact phylogenetic relationships.

\section{Acknowledgements}

The first author would like to thank her advisors Eitan Tchernov, Louis Jacobs, Dale Winkler, Anthony Fiorillo, John Ubelaker and Bonnie Jacobs, for their invaluable teaching and instruction, and Olivier Rieppel for support and instructive conversations. We thank Kent Newman, for his skillful preparation work, Roy Beavers, Ahuva Almogi, Yakov Arkin, Benjamin Buchbinder and Zeev Lewy, for assistance with the lithological and biostratigraphic analysis. We thank Nathalie Bardet and Rob Holmes for their helpful comments and suggestions. We thank the Institute for the Study of Earth and Man and the Department of Geological Sciences, Southern Methodist University, Dallas, Texas; and the Field Museum Visiting Scientist Scholarship, Chicago, Illinois, for financial support of this project.

\section{References}

Arkin, Y., 1976. Geological map of Jerusalem and vicinity 1:50,000. Geological Survey of Israel, Jerusalem.

Arkin, Y., Braun, M. \& Starinski, A., 1965. Type sections of Cretaceous formations in the Jerusalem-Bet Shemesh area. I. Lithostratigraphy. Stratigraphic Sections, 1. Geological Survey of Israel (Jerusalem): 1-26.

Arkin, Y. \& Hamaoui, M., 1967. The Judea group (upper Cretaceous) in central and southern Israel. Bulletin of the Geological Survey of Israel 42: 1-17.

Bahl, K.N., 1937. Skull of Varanus monitor. Records of the Indian Museum 39: 133-174.

Bardet, N., Pereda Suberbiola, X. \& Jalil, N.-E., 2003. A new mosasauroid (Squamata) from the Late Cretaceous (Turonian) of Morocco. Comptes Rendus Palevol 2: 607-616.

Bell, B.A., Murry, P.A. \& Osten, L.W., 1982. Coniasaurus 0wen, 1850 from North America. Journal of Paleontology 56: 520-524.

Bell, G.L. Jr., 1997. A phylogenetic revision of North America and Adriatic Mosasauroidea. In: Callaway, J.M. \& Nicholls, E.L. (eds): Ancient marine reptiles. Academic Press (San Diego): 293-332.

Buchbinder, B., Benjamini, C. \& Lipson-Benitah, S., 2000. Sequence development of Late Cenomanian-Turonian carbonate ramps, platforms and basins in Israel. Cretaceous Research 21: 813-843.

Caldwell, M.W., 1999. Description and phylogenetic relationships of a new species of Coniasaurus Owen, 1850 (Squamata). Journal of Vertebrate Paleontology 19: 438-455.

Caldwell, M.W., 2000. On the aquatic squamate Dolichosaurus longicollis Owen, 1850, (Cenomanian, Upper Cretaceous), and the evolution of elongate necks in squamates. Journal of Vertebrate Paleontology 20: 720-735.

Caldwell, M.W. \& Cooper, J.A., 1999. Redescription, palaeobiogeography and palaeoecology of Coniasaurus crassidens Owen, 1850 (Squamata) from the Lower Chalk (Cretaceous; Cenomanian) of SE England. Zoological Journal of the Linnean Society 127: 423-452.

Caldwell, M.W. \& Lee, M.S.Y., 2004. Reevaluation of the Cretaceous marine lizard Acteosaurus crassicostatus Calligaris, 1993. Journal of Paleontology 78: 617-619.

Carroll, R.L., 1997. Mesozoic marine reptiles as models of long-term, large-scale evolutionary phenomena. In: Callaway, J.M. \& Nicholls, E.L. (eds): Ancient marine reptiles. Academic Press (San Diego): 467-489.

Carroll, R.L. \& DeBraga, M., 1992. Aigialosaurs: mid-Cretaceous varanoid lizards. Journal of Vertebrate Paleontology 12(1): 66-86.

Dal Sasso, C. \& Pinna, G., 1997. Aphanizocnemus libanensis n. gen. n. sp., a new dolichosaur (Reptilia, Varanoidea) from the Upper Cretaceous of Lebanon. Paleontologia Lombarda 7: 3-31.

Dal Sasso, C. \& Renesto, S., 1999. Aquatic varanoid reptiles from the Cenomanian (Upper Cretaceous) lithographic limestones of Lebanon. Rivista del Museo civico di Scienze naturali 'E. Caffi', Bergamo 20: 63-69.

DeBraga, M. \& Carroll, R.L., 1993. The origin of mosasaurs as a model of macroevolutionary patterns and processes. Evolutionary Biology 27: 245-322.

Edmund, A.G., 1969. Dentition. In: Gans, C., Bellairs, A. D'A. \& Parsons, T.S. (eds): Biology of the Reptilia. Academic Press (London): 117-200. 
Estes, R., de Queiroz, K. \& Gauthier, J.A., 1988. Phylogenetic relationships within Squamata. In: Estes, R. \& Pregill, G. (eds): Phylogenetic relationships of the lizard families. Stanford University Press (Stanford, California): 119-281.

Frazzetta, T.H., 1962. A functional consideration of cranial kinesis in lizards. Journal of Morphology 111: 287-320.

Gauthier, J.A., Estes, R. \& De Queiroz, K., 1988. A phylogenetic analysis of Lepidosauromorpha. In: Estes, R. \& Pregill, G. (eds): Phylogenetic relationships of the lizard families. Stanford University Press (Stanford, California): 15-98.

Gradstein, F.M., Agterberg, F. P., Ogg, J. G., Hardenbol, J., Van Veer, P., Thierry, J. \& Huang, Z., 1995. A Triassic, Jurassic and Cretaceous time scale. In: Berggren, W.A., Kent, D.V., Aubry, M.-P. \& Hardenbol, J. (eds): Geochronology, time scales and global stratigraphic correlation. Society of Economic Paleontologists and Mineralogists, Special Publication 54: 95-126.

Hamaoui, M. \& Raab, M., 1965. Type sections of Cretaceous formations in the Jerusalem - Bet Shemesh area. II. Biostratigraphy. Geological Survey of Israel (Jerusalem): 27-39.

Hecht, M.K., 1975. The morphology and relationships of the largest known terrestrial lizard, Megalania prisca Owen, from the Pleistocene of Australia. Proceedings of the royal Society of Victoria 87: 239-249.

Holmes, R.B. \& Sues, H.-D., 2000. A partial skeleton of the basal mosasaur Halisaurus platyspondylus from the Severn Formation (Upper Cretaceous; Maastrichtian) of Maryland. Journal of Paleontology 74: 309-316.

Lee, M.S.Y., 1997. The phylogeny of varanoid lizards and the affinities of snakes. Philosophical Transactions of the Royal Society of London B352: 53-91.

Lee, M.S.Y. \& Caldwell, M.W., 2000. Adriosaurus and the affinities of mosasaurs, dolichosaurs and snakes. Journal of Paleontology 74: 915-937.

Lee, M.S.Y. \& Scanlon, J.D., 2002. The Cretaceous marine squamate Mesoleptos and the origin of snakes. Bulletin of the Natural History Museum (Zoology) 68: 131-142.

Lewy, Z., 1989. Correlation of lithostratigraphic units in the upper Judea Group (Late Cenomanian-Late Coniacian). Israel Journal of Earth Sciences 38: 37-43.

Lewy, Z., 1996. The approximate position of the Middle-Upper Cenomanian substage boundary in Israel. Israel Journal of Earth Sciences 45: 193-199.

MCDowell, S.B. \& Bogert, C.M., 1954. The systematic position of Lanthanotus and the affinities of anguimorphan lizards. Bulletin of the American Museum of Natural History 105: 1-142.

Nopcsa, F., 1903. Ueber die varanusartigen Lacerten Istriens. Beitrage zur Paläontologie und Geologie Oesterreich-Ungarns und des Orients 15: 31-42.

Norell, M.A., McKenna, M.C. \& Novacek, M.J., 1992. Estesia mongolensis, a new fossil varanoid from the Late Cretaceous of the Barun Goyot Formation of Mongolia. American Museum Novitates 3045: 1-24.

Pierce, S.E. \& Caldwell, M.W., 2004. Redescription and phylogenetic position of the Adriatic (Upper Cretaceous: Cenomanian) dolichosaur Pontosaurus lesinensis Kornhuber, 1873. Journal of Vertebrate Paleontology 24: 373-386.

Polcyn, M.J., Tchernov, E. \& Jacobs, L.L., 1999. The Cretaceous biogeography of the eastern Mediterranean with a description of a new basal mosasauroid from ‘Ein Yabrud, Israel. In: Tomida, Y., Rich, T.H. \& Vickers-Rich. P. (eds): Proceedings of the Second Gondwanan Dinosaur Symposium. National Science Museum Tokyo, Monographs 15: 259-290.

Polcyn, M.J., Tchernov, E. \& Jacobs, L.L., 2003. Haasiasaurus gen. nov., a new generic name for the basal mosasauroid Haasia Polcyn et al., 1999. Journal of Vertebrate Paleontology 23: 476.
Pregill, G., Gauthier, J.A. \& Greene, H.W., 1986. The evolution of helodermatid squamates, with description of a new taxon and an overview of Varanoidea. Transactions of the San Diego Society of Natural History 21: 167-202.

Raab, M., 1958. The fishes from the Upper Cenomanian in the Jerusalem area. Hebrew University of Jerusalem (Jerusalem): 58 pp. (unpubl. MSc thesis).

Raab, M. \& Chalifa, Y., 1987. A new enchodontid fish genus from the Upper Cenomanian of Jerusalem, Israel. Palaeontology 30: 717-731.

Rieppel, O., 1980. The phylogeny of anguimorph lizards. Denkschriften der schweizerischen naturforschenden Gesellschaft 94: 1-86.

Rieppel, O., Zaher, H., Tchernov, E. \& Polcyn, M.J., 2003. The anatomy and relationships of Haasiophis terrasanctus, a fossil snake with well-developed hind limbs from the mid-Cretaceous of the Middle East. Journal of Paleontology 77: 536-558.

Russell, D.A., 1967. Systematics and morphology of American mosasaurs (Reptilia, Sauria). Bulletin of the Peabody Museum of Natural History, Yale University 23: 1-237.

Taitel-Goldman, N., Heller-Kallai, L. \& Sass, E., 1995. Clay minerals and feldspars in argillaceous strata of the Judea Group in the Jerusalem Hills. Israel Journal of Earth Sciences 44: 71-79.

Zaher, H. \& Rieppel, 0., 1999. Tooth implantation and replacement in squamates, with special reference to mosasaur lizards and snakes. American Museum Novitates 3271: 1-19. 